\title{
Mex3c mutation reduces adiposity partially through increasing physical activity
}

\author{
Changjie Han ${ }^{1,2}$, Yan Jiao', Qingguo Zhao' and Baisong Lu' \\ ${ }^{1}$ Institute for Regenerative Medicine, Wake Forest University Health Sciences, Medical Center Boulevard, \\ Winston-Salem, North Carolina 27157, USA \\ ${ }^{2}$ Department of Human Anatomy and Embryology, The Second Military Medical University, Shanghai 200433, China
}

Correspondence should be addressed

to B Lu

Email

blu@wakehealth.edu

\begin{abstract}
MEX3C is an RNA-binding protein with unknown physiological function. We have recently reported that a Mex3c mutation in mice causes growth retardation and reduced adiposity, but how adiposity is reduced remains unclear. Herein, we show that homozygous Mex3c gene trap mice have increased physical activity. The Mex3c mutation consistently conferred full protection from diet-induced obesity, hyperglycemia, insulin resistance, hyperlipidemia, and hepatic steatosis. In ob/ob mice with leptin deficiency, the Mex3c mutation also increased physical activity and improved glucose and lipid profiles. Expressing cre in the neurons of $M e x 3 c$ gene trap mice, an attempt to partially restoring neuronal Mex3c expression, significantly increased white adipose tissue deposition, but had no effects on body length. Our data suggest that one way in which Mex3c regulates adiposity is through controlling physical activity, and that neuronal Mex3c expression could play an important role in this process.
\end{abstract}
Key Words
- Mex3c
- mice
- physical activity
- adiposity
- high-fat diet

\section{Introduction}

Caenorhabditis elegans MEX3 is an hnRNP K homology $(\mathrm{KH})$ domain-containing RNA-binding protein (Siomi et al. 1993), regulating RNA targets such as pal1 (Draper et al. 1996, Hunter \& Kenyon 1996, Huang et al. 2002), rme2 (Ciosk et al. 2004), and nos2 (Jadhav et al. 2008). It is involved in the cell fate specification process in C. elegans, or in totipotency maintenance of the germline in adult worms (Draper et al. 1996, Hunter \& Kenyon 1996, Musco et al. 1996, Ciosk et al. 2006). Human and mouse genomes encode four MEX3 homologues: MEX3A, MEX3B, MEX3C, and MEX3D (Buchet-Poyau et al. 2007). They all have KH RNA-binding domains in the N-terminus (also present in the C. elegans homolog) and a zinc finger domain at the C-terminus (absent in MEX3 in C. elegans).
MEX3C contributes to genetic susceptibility to hypertension, as shown by linkage analysis and association studies (Guzman et al. 2006). It is also a cancer chromosomal instability-repressor gene (Burrell et al. 2013). The mechanisms for both observations are unknown. Human MEX3C enhances the degradation of HLA-A2 mRNA through binding to its 3' UTR (Cano et al. 2012, Cano \& Lehner 2013). These reports suggest that MEX3C has multiple functions, most likely through regulation of different mRNA targets in different cell types.

Mouse Mex $3 c$ is highly similar to its human homolog. We generated Mex3c gene trap mice on a C57BL/6 background; homozygous mutant mice had a high postnatal death rate, possibly due to poorly expanded

Published by Bioscientifica Ltd 
lungs (Jiao et al. 2012a). We bred mice to a mainly FVB/N background; homozygous Mex3c mutant mice on this background survived to adulthood and were fertile. However, these mice show growth retardation associated with IGF1 deficiency in developing bones (Jiao et al. 2012a), and reduced adiposity due to increased energy expenditure (Jiao et al. 2012b). Herein, we further examined the effects of Mex3c mutation on physical activity and diet-induced obesity, and explored the roles of neuronal Mex3c in this process through expressing $M e x 3 c$ in neurons of Mex3c mutant mice, an attempt to partially restore Mex $3 c$ expression.

\section{Materials and methods}

\section{Animals}

The Mex3c gene trap allele (Mex3c $c^{G t(D D 0642) W t s i}$, written as ' $t r$ ' herein, indicating the trapped allele) was described earlier (Jiao et al. 2012a). Lep ${ }^{o b / o b}$ mice (Zhang et al. 1994) and mice with rat Synapsin I promoter-driven Cre (Syn1-Cre; Zhu et al. 2001) were purchased from the Jackson Laboratory (Bar Harbor, ME, USA). Mex $3 c^{+/ t r}$; Lep ${ }^{+/ o b}$ mice were intercrossed to obtain Mex3c/Leptin double-mutant mice. Mex $3 c^{+/ t r}$;Syn1-Cre ${ }^{+}$mice were intercrossed to obtain $M e x 3 c^{t r / t} ;$;Syn1-Cre ${ }^{+}$and Mex3 ${ }^{\text {tr/tr}} ;$; Syn1-Cre ${ }^{-}$mice. All mice were backcrossed at least five generations to a mainly $\mathrm{FVB} / \mathrm{N}$ background. The experiments were conducted in accordance with the National Research Council publication Guide for Care and Use of Laboratory Animals, and approved by the Institutional Animal Care and Use Committee of Wake Forest University Health Sciences. A chow diet (Prolab RMH3000, PMI Nutrition International, Henderson, CO, USA) was used for colony maintenance. A high-fat diet (HFD, TD.08811, Harlan), with 14.8, 40.6, and 44.6\% calories from protein, carbohydrate, and fat, respectively, was used to induce obesity. Diet administration started when mice were 5-6 weeks old and lasted for 12-16 weeks. Mouse genotyping was performed using lysates of ear biopsies, as previously described (Agoulnik et al. 2002, Jiao et al. 2012a).

\section{Food consumption}

Mice were singly caged in cages with lifted wire bottoms for food intake assays. Any food spilled on the bottom of the cages was recovered and subtracted from food intake. Food intake was assayed 1 week after starting the high-fat diet, and normalized to body mass. This normalization is suitable because at the time of assaying, all mice have comparable white adipose tissue (WAT) accumulation.

\section{Monitoring physical activity}

Locomotor activity was monitored using the Oxymax CLAMS system (Columbus Instruments, Columbus, OH, USA) when animals were 3 months old. A photobeambased activity-monitoring system detected and recorded ambulatory ( $x$ and $y$ axes) and rearing ( $z$ axis) movements. The temperature of the cabinet was $23^{\circ} \mathrm{C}$. All parameters were measured continuously and simultaneously for $72 \mathrm{~h}$ after $24 \mathrm{~h}$ of adaptation in singly housed mice. Three-day averages for each mouse were used for analysis.

\section{Glucose and insulin tolerance tests}

Mice were fasted for $16 \mathrm{~h}$ for glucose tolerance tests and $6 \mathrm{~h}$ for insulin tolerance tests. Just before glucose or insulin injection, tail vein blood glucose was measured with the ACCU-CHEK active meter and Test Strips (Roche). After mice received an i.p. injection of $10 \%$ D-glucose (Sigma, $1 \mathrm{~g} / \mathrm{kg}$ body weight), or insulin (Novo Nordisk, $0.75 \mathrm{U} / \mathrm{kg}$, pre-diluted to $2.5 \mathrm{U} / \mathrm{ml}$ in $0.9 \% \mathrm{NaCl}$ ), blood glucose levels were measured 30, 60, 90, and 120 min post-injection.

\section{Blood biochemical assays}

Plasma was collected from mice fasted for $4 \mathrm{~h}$. Commercial kits were used to assay concentrations for blood triglycerides, cholesterol (Cayman Chemical, Ann Arbor, MI, USA), and insulin (Mercodia, Uppsala, Sweden).

\section{Intestinal fat absorption}

After 10 weeks of high-fat diet treatment, male mice were fed a test diet similar to TD.08811 (TD.10816; Harlan, Indianapolis, IN, USA), except $5 \%$ of fat in TD.08811 was replaced by the nonabsorbable sucrose polybehenate (Jandacek et al. 2004). After 5 days on the test diet, fecal samples of individually caged mice were collected for 3 days. The fatty acid content and composition in both the diet and feces were determined by gas chromatography (Section on Lipid Sciences, Wake Forest University Health Sciences), and the fractional absorption of total and individual fatty acids was calculated as described previously (Jandacek et al. 2004).

\section{WAT and liver tissue histology}

Adipose and liver tissues were fixed in $4 \%$ paraformaldehyde at $4{ }^{\circ} \mathrm{C}$ overnight for cryosections and paraffin sections. For histological analyses of WAT and liver,

Published by Bioscientifica Ltd. 
5-8 $\mu \mathrm{m}$ paraffin sections were stained with hematoxylin and eosin. To quantify adipocyte size, 100 adipocytes from each of three mice per group were sampled. Three to four nonsuccessive sections were sampled for each mouse. Adipocyte size was analyzed by ImageJ software on digital images taken under the same magnification.

\section{Quantitative PCR analysis of gene expression and mitochondrial DNA content}

Total RNA was extracted from epididymal WAT and brown adipose tissues (BAT) of male mice, treated with Turbo DNase (Ambion, Thermo Fisher Scientific, Waltham, MA, USA) to eliminate DNA, and reverse transcribed as described previously (Jiao et al. 2012a). Sybr Green $2 \times$ PCR mixture (Applied Biosystems) was used for detecting Ppib, Pgc1 $\alpha$ (Ppargc1 $\alpha$ ), Ppary, Ucp1, Ucp2, Cd137 (Tnfrsf9), and Tmem26 expression with specific primers described previously (Jiao et al. 2012b, Wu et al. 2012). Hprt1 and Ucp1 Taqman probes (Applied Biosystems) were also used. Five mice from each group were analyzed. Mean \pm s.E.M. were obtained from three to four independent PCR analyses. Hprt1 and Ppib were used as internal controls and obtained similar results.

Quantitative PCR was used to compare the mtDNA content of epididymal WAT and BAT. Total DNA was isolated from tissues with the DNeasy Blood and Tissue Kit (Qiagen). ND5F and ND5R primers amplifying an $87 \mathrm{bp}$ region of the $m t-N d 5$ gene were used to amplify the mtDNA. 18sRNA Taqman probe (Applied Biosystems) and Gapdh primers, which gave similar results in qPCR, were used for amplifying genomic DNA. Sequences for the primers were described previously (George et al. 2012).

\section{Statistical analysis}

Two-tailed Student's $t$-tests were performed to compare the means of two groups. Tukey's post-tests following
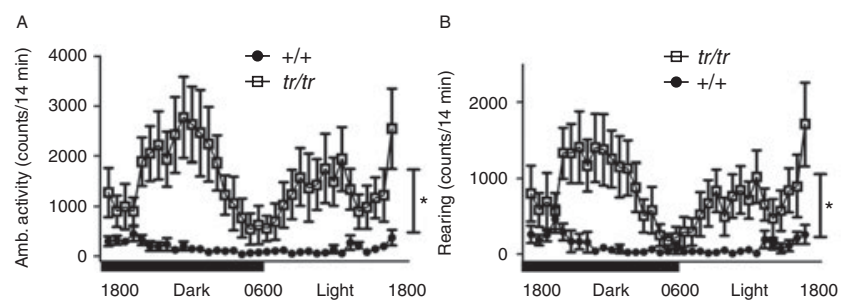

\section{Figure 1}

tr/tr mice have increased physical activity compared with normal mice. (A) Ambulatory (Amb.) activity of $+/+$ and tr/tr males. (B) Rearing activity of control and mutant males. (C) Ambulatory activities of ob/ob mice and double-mutant males. (D) Rearing activity of ob/ob mice and double-
ANOVA were performed for the means of more than two groups. For repeated measurements, two-way ANOVA was performed followed by Bonferroni post-tests. $P<0.05$ was accepted as statistically significant.

\section{Results}

\section{Mex3c mutation significantly increases physical activity}

Previously, we observed that heterozygous Mex3c gene trap mice $\left(+/ t r\right.$, $t r^{\prime}$ indicates the trapped allele for simplicity) have increased energy expenditure but normal physical activities. Physical activities of homozygous mutant mice $(t r / t r)$ were examined to determine whether Mex $3 c$ has a dose effect on locomotor activities. In contrast to $+/$ tr mice's normal physical activity reported previously (Jiao et al. 2012b), tr/tr mice showed significantly increased ambulatory activity (Fig. 1A) and rearing activity (Fig. 1B) compared with $+/+$ mice. Thus, the Mex3c mutation was associated with significantly increased physical activity.

$\mathrm{tr} / \mathrm{tr}$ mice have normal body temperature (Jiao et al. $2012 b$ ). As they have reduced adiposity, we wondered whether they increase activity to maintain normal temperature. We previously observed that $t r / t r ; o b / o b$ mice were obese (Jiao et al. 2012b). Physical activity of $\mathrm{tr} / \mathrm{tr} ; o b / o b$ mice was also significantly increased compared with $o b / o b$ mice and $+/+$ mice (Fig. $1 \mathrm{C}$ and D).

\section{Mex3c mutation prevents diet-induced obesity}

These findings prompted us to examine the effects of Mex3c mutation on diet-induced obesity. Mutant mice were fed a high-fat diet. As $t r / t r$ mice were growth retarded (Jiao et al. 2012a), they weighed significantly less than agematched $+1+$ mice at all time points regardless of diet (Fig. 2A and B). After 5 weeks on the high-fat diet, $+/+$ males gained significantly more weight than those on
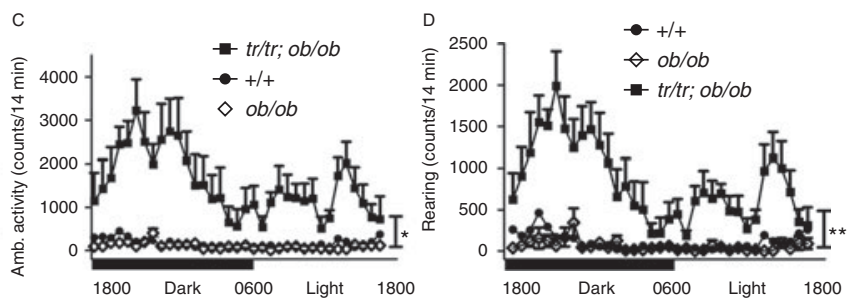

mutant males. Mean \pm s.E.M. are presented. $* P<0.05$ and $* * P<0.01$ by two-way ANOVA. (C and D) Data from $+/+$ mice were also included for reference. Mice ( $n \geq 5 /$ group) were 3 months old.

Published by Bioscientifica Ltd. 
A

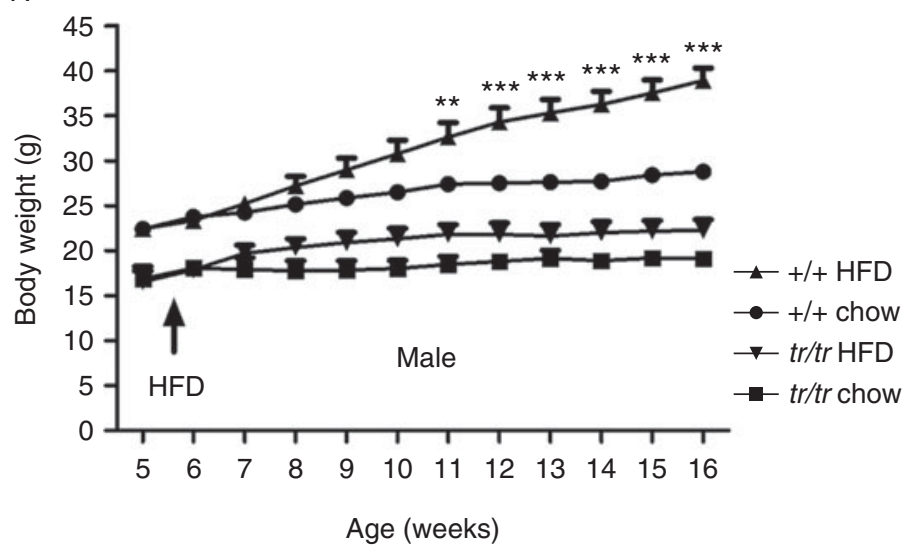

B

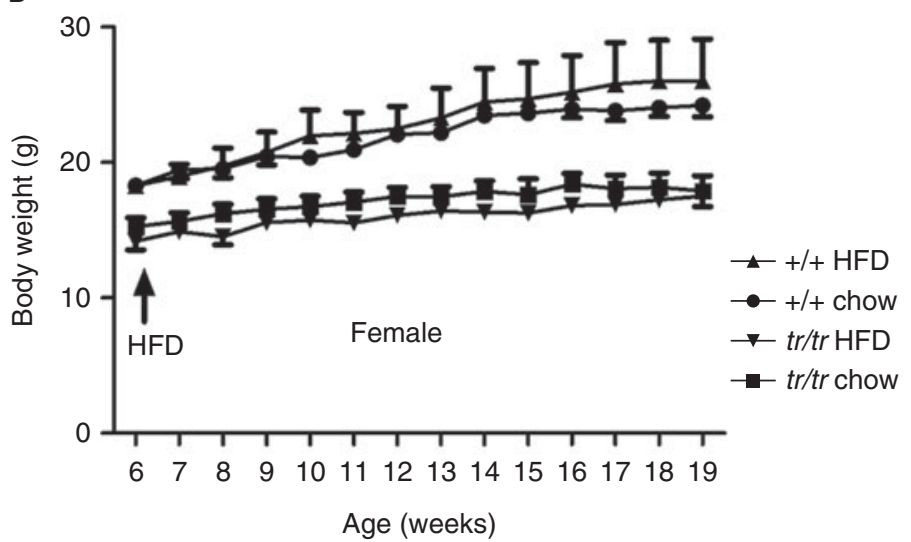

E

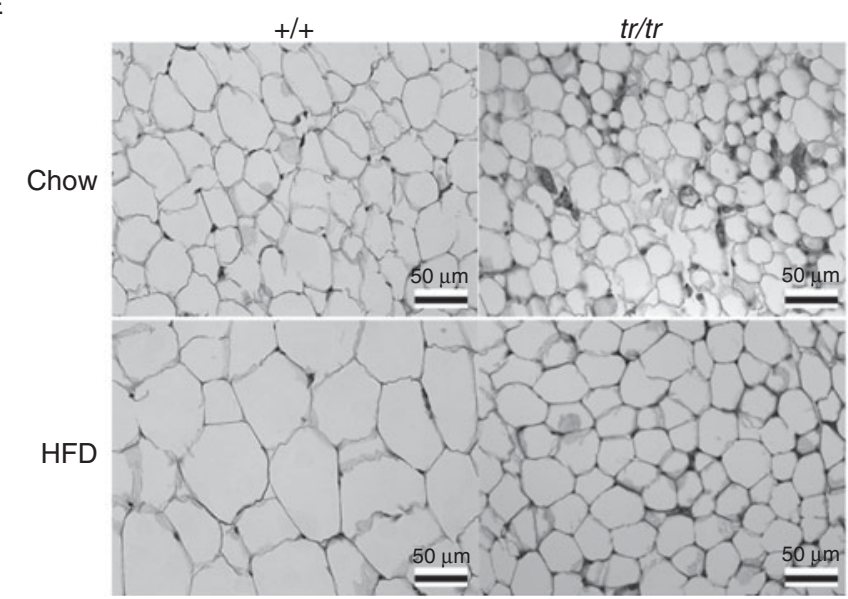

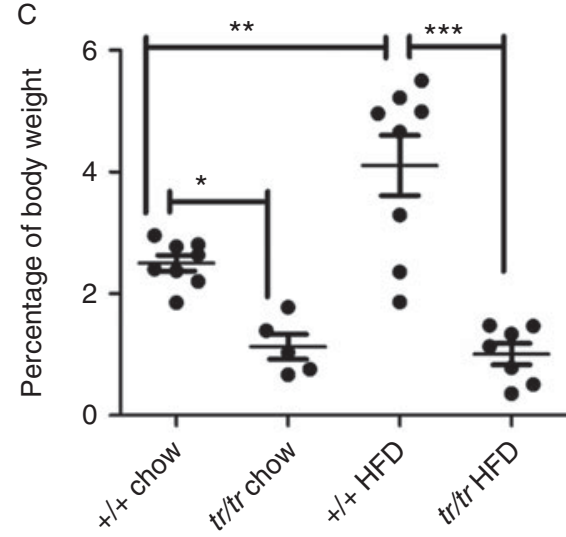

D

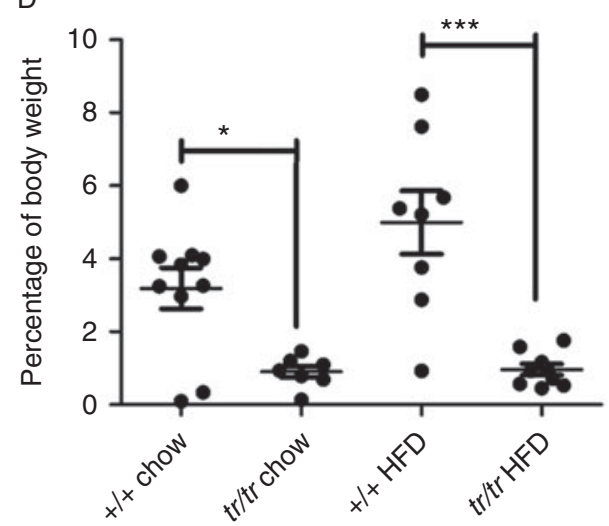

$\mathrm{F}$

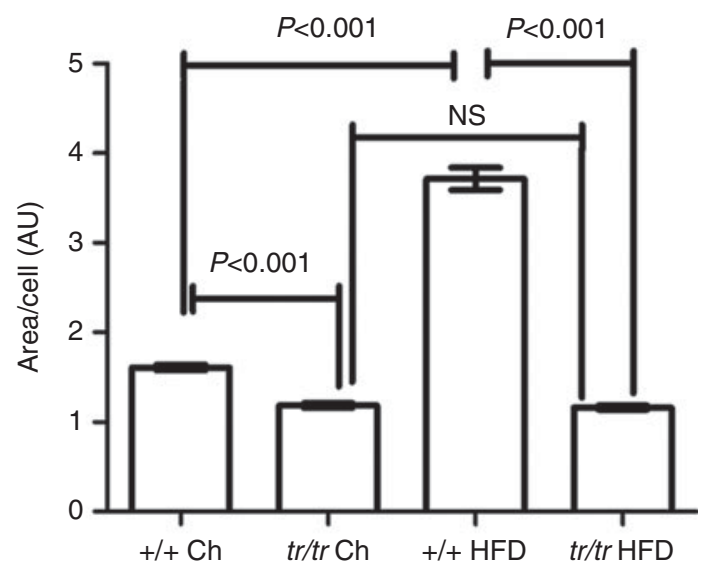

Figure 2

Mex3c mutant mice are resistant to diet-induced obesity. (A and B) Growth curves of male (A) and female (B) mice on chow or a high-fat diet (HFD). Six or more animals were tested at each time point. (C and D) Percentage of epididymal and parametrial WAT relative to body weight in male (C) and female (D) mice. Each circle represents one animal. (E) Hematoxylin and eosin (H\&E)-stained epididymal WAT sections (representative of five mice observed per group). Scale bar: $50 \mu \mathrm{m}$. (F) WAT adipocyte sizes in

http://joe.endocrinology-journals.org DOI: 10.1530/JOE-14-007 (c) 2014 Society for Endocrinology Printed in Great Britain epididymal tissues from control and mutant mice. 300 adipocytes from three mice (100 cells from five different fields per mouse) from each group were sampled and analyzed by ImageJ software. AU, arbitrary unit. Mean \pm s.E.M. are presented except in (E) NS, no significant difference. $* P<0.05, * * P<0.01$, and $* * * P<0.0001$ by Bonferroni post-tests (A, HFDfed vs chow-fed $+I+$ mice) or Tukey's multiple comparison tests ( $C, D$ and $F$ ) following ANOVA.

Published by Bioscientifica Ltd. 
chow diet (Fig. 2A). By contrast, tr/tr males did not gain more weight than those on chow diet even after 12 weeks on the high-fat diet. Male mice on an FVB/N background are sensitive to diet-induced obesity, but female mice on this background are not (Hu et al. 2004, Chen et al. 2005). Consistently, the high-fat diet was not associated with significant weight gain even in $+/+$ female mice (Fig. 2B).

After 12 weeks on the high-fat diet, $+/+$ males accumulated significantly more epididymal WAT than those on the chow diet (Fig. 2C), while tr/tr males did not. The diet treatment increased parametrial WAT mass in some $+/+$ females, but overall the difference was not significant due to large intra-group variations. Parametrial WAT was not changed in any $t r / t r$ female mice (Fig. 2D). Treatment significantly increased adipocyte size in male $+/+$ mice, but not in male tr/tr mice (Fig. 2E and F). In female, $+/+$ mice fed the high-fat diet, the size of adipocytes increased only in those that became obese (two females examined) but not those remained nonobese (two females examined). Adipocyte size did not increase in the four high-fat diet-fed $t r / t r$ female mice examined.

As reported previously (Jiao et al. 2012b), the absolute amount of food consumed by $\mathrm{tr} / \mathrm{tr}$ mice was reduced compared with normal control mice. However, food intake per gram body mass did not differ between the two groups (Table 1). Control mice absorbed $97 \pm 0.7 \%$ of total lipids from high-fat diet $(n=4)$ and mutant mice absorbed $94.6 \pm 1.0 \%$ of total lipids from that diet $(n=4)$. Considering the sensitivity and variation of the assay and the fact that over $94 \%$ of total food lipids were absorbed by both groups, it is unlikely that the lean phenotype of $t r / t r$ mice was caused by the differences in lipid absorption.

\section{Mex3c mutation improves blood glucose and lipid maintenance on high-fat diet}

After 12 weeks on the high-fat diet, male $+/+$ mice had significantly higher blood glucose concentrations than $+/+$ mice on chow diet, as well as male $t r / t r$ mice on either diet (Fig. 3A). The diet treatment did not change blood glucose concentrations in $t r / t r$ males. Although $+/+$ male mice on the high-fat diet had hyperinsulinemia, $t r / t r$ males on that diet had insulin levels similar to chow-fed $t r / t r$ males (Fig. 3B). The high-fat diet caused glucose intolerance in $+/+$ males but not in $t r / t r$ males (Fig. 3C and D), as well as insulin resistance in $+/+$ males, but not in $t r / t r$ males (Fig. 3E and F). $+/+$ females had higher blood glucose concentrations than $\mathrm{tr} / \mathrm{tr}$ females on either diet (Fig. 3G). The high-fat diet failed to induce hyperglycemia (Fig. 3G) or hyperinsulinemia (Fig. 3H) in most $+/+$ females.

Plasma triglyceride concentrations in $+/+$ males fed both diets were similar, and both were significantly higher than that in $t r / t r$ mice (Fig. 4A). Although the diet treatment increased total plasma cholesterol concentrations in $+/+$ and $t r / t r$ males (Fig. 4B), the increase was larger in $+/+$ males $(84 \mathrm{mg} / \mathrm{dl})$ than in $\mathrm{tr} / \mathrm{tr}$ males $(59.6 \mathrm{mg} / \mathrm{dl})$. In addition, plasma cholesterol concentrations of $t r / t r$ males on the high-fat diet were not significantly different from those of chow-fed $+/+$ males, but they were significantly lower than those of $+/+$ males on the high-fat diet (Fig. 4B). Both $t r / t r$ and $+/+$ females on the high-fat diet had lower plasma triglyceride concentrations than their counterparts on the chow diet (Fig. 4C). The high-fat diet significantly increased total plasma cholesterol concentrations in $+/+$ but not $t r / t r$ females (Fig. 4D).

\section{Normal mitochondrial and beige cell content in adipose tissues of Mex3c mutant mice}

Mitochondrial content in WAT or BAT did not differ between $+/+$ and $t r / t r$ mice (Fig. 4E). The high-fat diet similarly reduced mitochondrial DNA content in WAT of $+/+$ and $t r / t r$ mice, consistent with previous observations on normal mice (Sutherland et al. 2008). The high-fat diet also significantly increased mitochondrial DNA content in BAT of normal mice, but not in tr/tr mice (Fig. 4E).

Table 1 Food intake of control and mutant mice. Each group had six or more mice. Mean \pm s.E.M. are presented

\begin{tabular}{|c|c|c|c|c|c|}
\hline \multirow[b]{2}{*}{ Sex } & \multirow[b]{2}{*}{ Diet } & \multicolumn{2}{|c|}{ Food intake (g/mouse per day) } & \multicolumn{2}{|c|}{ Daily food intake/body weight } \\
\hline & & $+1+$ & tr/tr & $+1+$ & tr/tr \\
\hline \multirow[t]{2}{*}{ Male } & Chow & $4.6 \pm 0.25$ & $3.0 \pm 0.17 * *$ & $0.18 \pm 0.01$ & $0.17 \pm 0.01$ \\
\hline & HFD & $4.0 \pm 0.74$ & $2.5 \pm 0.11 * *$ & $0.14 \pm 0.03$ & $0.12 \pm 0.01$ \\
\hline \multirow[t]{2}{*}{ Female } & Chow & $3.9 \pm 0.25$ & $2.9 \pm 0.14 * *$ & $0.18 \pm 0.01$ & $0.17 \pm 0.01$ \\
\hline & HFD & $2.9 \pm 0.16$ & $2.1 \pm 0.14^{*}$ & $0.14 \pm 0.01$ & $0.15 \pm 0.01$ \\
\hline
\end{tabular}

http://joe.endocrinology-journals.org DOI: 10.1530/JOE-14-0071
(C) 2014 Society for Endocrinology Printed in Great Britain
Published by Bioscientifica Ltd 

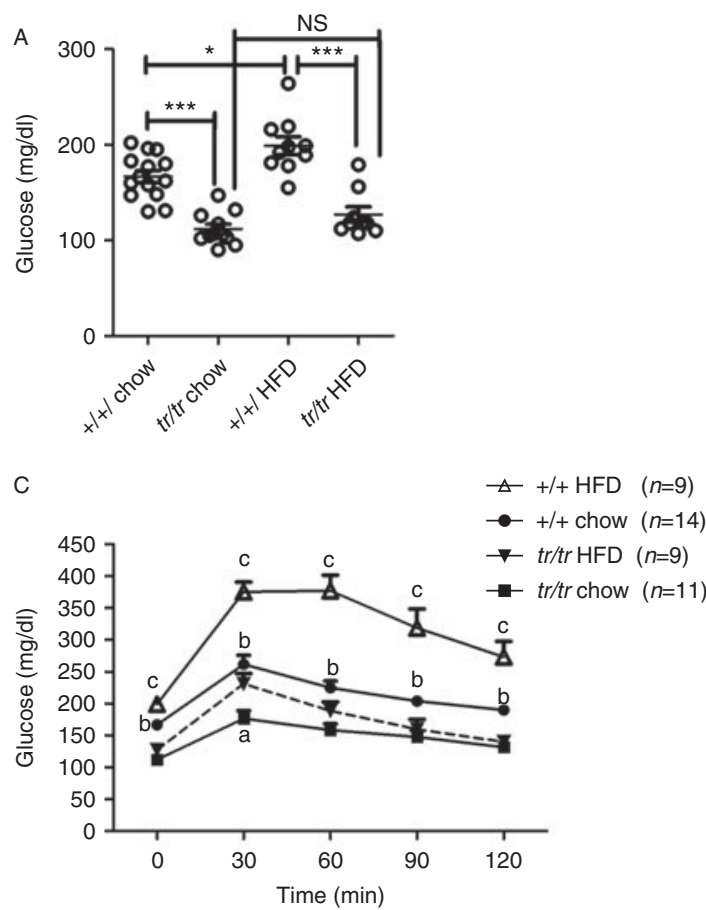

E

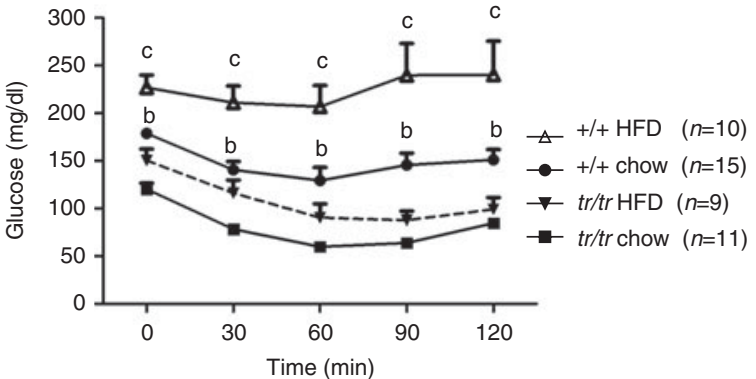

G

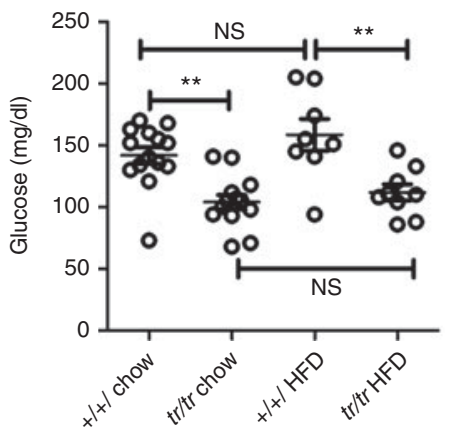

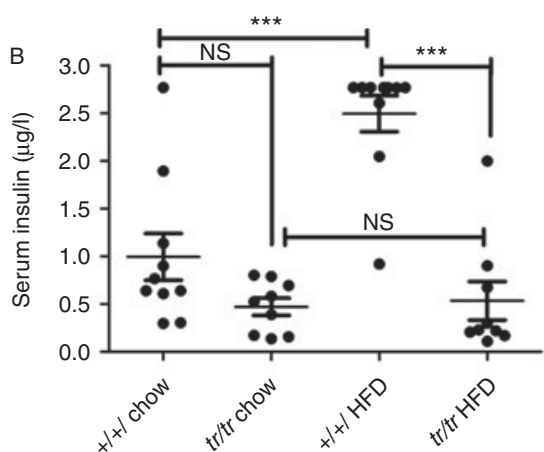

D
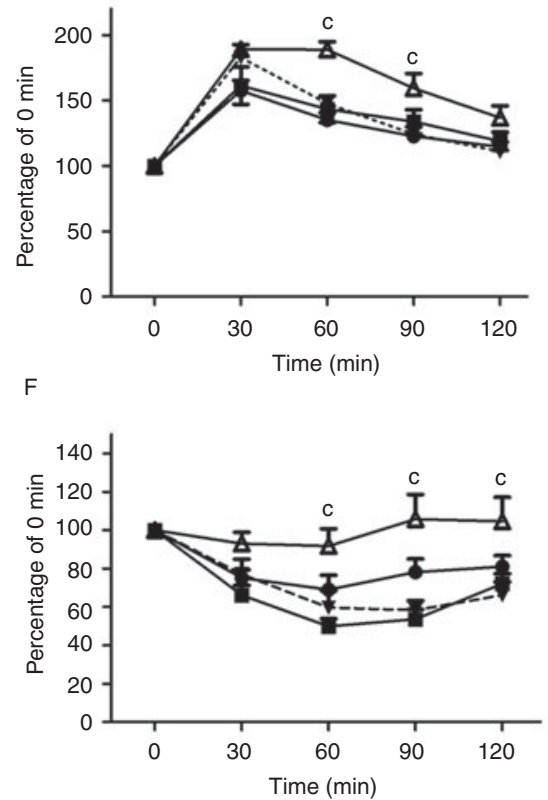

$\mathrm{H}$

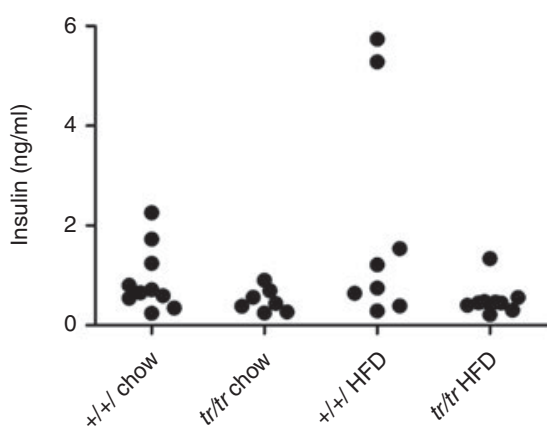

Figure 3

Mex3c mutation prevents diet-induced glucose intolerance and insulin resistance. (A and $B$ ) Hyperglycemia (A) and hyperinsulinemia (B) occurred in $+/+$ but not tr/tr males on the high-fat diet (HFD) vs chow diet. (C and D) Glucose intolerance occurred in $+/+$ but not $t r / t r$ males on the high-fat diet (HFD) vs chow diet. As baseline blood glucose levels differed among groups (C), data are also presented as relative values normalized to time 0 (D). (E and F) Insulin resistance occurred in control but not mutant males on the high-fat diet (HFD). Data are also presented as relative values normalized to time 0 in F. (G and H) Glucose $(G)$ and insulin $(H)$ concentrations of female mice on Printed in Great Britain different diets. For $C, D, E$ and $F$, animal numbers $(n)$ in each group are listed. ${ }^{a}$ Significant difference between chow-fed $t r / t r$ mice vs HFD-fed tr/tr mice; bsignificant differences between chow-fed tr/tr mice vs chow-fed $+/+$ mice;

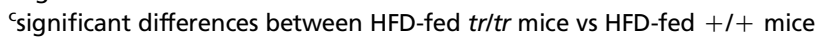
$(P<0.05$ by Bonferroni post-tests following two-way ANOVA). For A, B, G, and $\mathrm{H}$, each circle represents one mouse and mean \pm S.E.M. are indicated. $* P<0.05, * * P<0.01$, and $* * * P<0.0001$ by Tukey's multiple comparison test following one-way ANOVA. Blood glucose and insulin were measured after 16 and $6 \mathrm{~h}$-fasting respectively.

Published by Bioscientifica Ltd. 

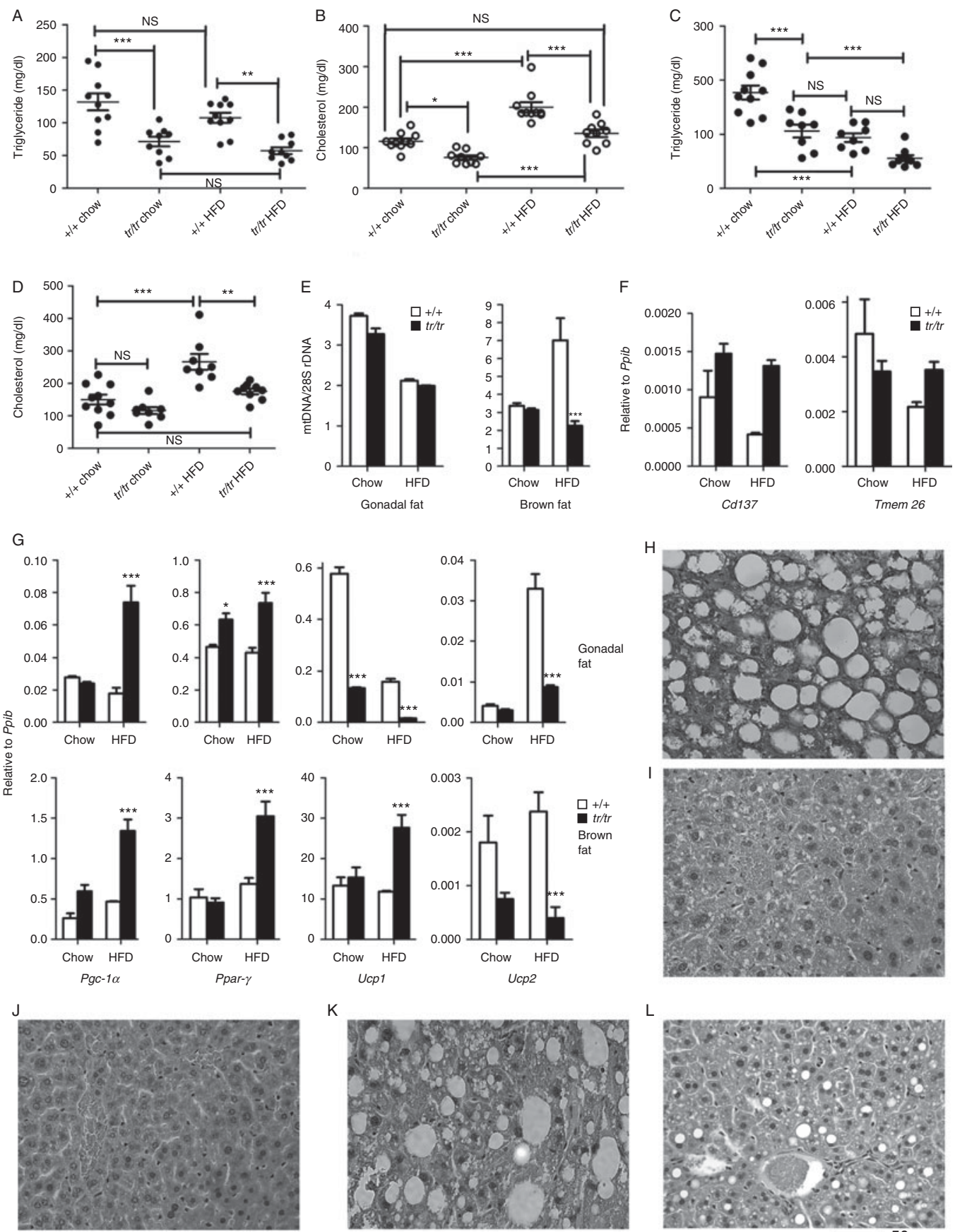

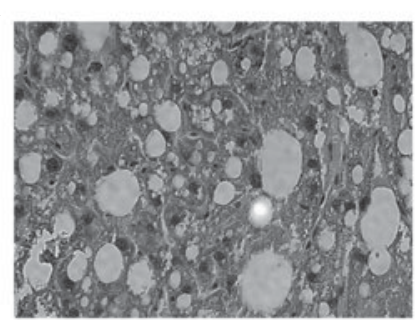

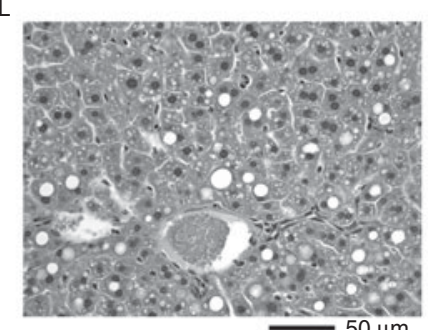

Figure 4

Biochemical and histological analyses of tissues from mutants on high-fat diet. (A) Blood triglyceride concentrations of control and mutant males.

(B) Total cholesterol concentrations of control and mutant males. (C) Blood triglyceride concentrations of female mice. (D) Blood cholesterol concentrations of female mice. (E) Mitochondrial DNA content by quantitative PCR. 28S rDNA was used as the genomic DNA control. (F) Beige cell composition in epididymal WAT by quantitative RT-PCR. Cd137 and Tmem26 were beige cell markers; Ppib was the internal control. (G) Pgc1, Ppary, Ucp1, and Ucp2 expression by quantitative RT-PCR. (H) Liver tissue from $\mathrm{a}+/+$ male mouse on high-fat diet showing macrovesicular steatosis (hematoxylin and eosin stained). (I) Liver tissue from a tr/tr male mouse Printed in Great Britain showing microvesicular steatosis. (J) Liver tissue from a tr/tr male mouse without steatosis. (K) Liver tissue from a $+I+$ female mouse showing macrovesicular steatosis. (L) Liver tissue from a tr/tr female mouse with the worst steatosis. In $A, B, C$, and $D$, each circle represents one mouse; mean \pm S.E.M. are indicated. $* P<0.05, * * P<0.01$, and $* * * P<0.0001$ by Tukey's multiple comparison test following one-way ANOVA. ns, no significant difference. In $E_{1} F$, and G, mean \pm s.E.M. of 3-5 independent PCR assays are presented. Equal amounts of DNA (E) or RNA ( $F$ and $G)$ from each mouse ( $n=5 /$ group) were used for quantitative PCR. ${ }^{*} P<0.05, * * P<0.01$, and, $* * * P<0.0001$ for $+I+$ mice vs $t r /$ tr mice on the same diet analyzed by two-way ANOVA.

Published by Bioscientifica Ltd. 
Beige cells are thermogenic cells in WAT (Petrovic et al. 2010), and Cd137 and Temem 26 are markers for these cells (Wu et al. 2012). The expression of these two genes was not increased in tr/tr mice (Fig. 4F), excluding the possibility that WAT contained more beige cells.

In mice on the high-fat diet, $t r / t r$ mice had significantly higher expression of Pgc1 $\alpha$ and Ppary in both types of adipose tissues when compared with $+/+$ mice (Fig. 4G). The high-fat diet did not change Ucp1 expression in the BAT of $+/+$ mice, but significantly increased its expression in $t r / t r$ mice. Epididymal WAT of control and mutant mice had lower but detectable Ucp1 expression compared with BAT (assayed both with specific Ucp1 primers and Ucp1 Taqman probe), but it was reduced in $t r / t r$ epididymal WAT regardless of diet. Ucp2 expression in both tissues was significantly downregulated in $\mathrm{tr} / \mathrm{tr}$ mice on the high-fat diet. Increased expression of $P g c 1 \alpha$ and Ppary in the adipose tissues of $t r / t r$ mice on a high-fat diet is consistent with their resistance to diet-induced obesity and associated metabolic syndromes. The expression profiles of $U c p 1$ and $U c p 2$ in $t r / t r$ suggest that they do not play a major role in the leanness of the $t r / t r$ mice.

\section{Mex3c mutation prevents diet-induced steatosis}

Hepatic steatosis was not seen in chow-fed $+/+$ and $t r / t r$ mice. However, macrovesicular steatosis was observed in over $50 \%$ of hepatic lobules of the $4+/+$ males we examined on the high-fat diet (Fig. $4 \mathrm{H}$ ), but in none of the $4 \mathrm{tr} / \mathrm{tr}$ males on that diet. Of the $4 \mathrm{tr} / \mathrm{tr}$ males on high-fat diet, only one showed microvesicular steatosis (Fig. 4I), and the rest had normal livers (Fig. 4J). Six of seven female $+/+$ mice on the high-fat diet showed steatosis, five of which had macrovesicular steatosis (Fig. 4K). On the contrary, four of the seven female $\mathrm{tr} / \mathrm{tr}$ mice on the high-fat diet had only milder hepatic damage (Fig. 4L) and the rest three mice had no steatosis at all.

\section{Mex3c mutation improves glucose and lipid profiles of ob/ob mice}

The effects of $M e x 3 c$ mutation on metabolism were further examined in $o b / o b$ mice. $t r / t r ; o b / o b$ mice had a similar percentage of WAT to lean tissue and similar histologic features of WAT as those of $o b / o b$ mice (data not shown). However, blood glucose levels of $t r / t r ; o b / o b$ mice, although higher than those of normal mice, were significantly lower than those of $o b / o b$ mice (Table 2). Insulin levels of $o b / o b$ and $t r / t r ; o b / o b$ mice were both higher than those of normal control mice; in $t r / t r ; o b / o b$ mice, they fell between levels of normal control mice and ob/ob mice. Blood triglycerides and total cholesterol concentrations were both lower in $t r / t r ; o b / o b$ mice than in $o b / o b$ mice. We confirmed our previous findings of no or milder steatosis in $t r / t r ; o b / o b$ mice than in $o b / o b$ mice (Jiao et al. 2012b; data not shown).

\section{Synapsin 1 promoter-controlled cre expression significantly increases adiposity of $t r / t r$ mice}

The gene trap vector in $t r / t r$ mice contains two loxP sites, flanking the splicing acceptor (SA) sequences that disrupt normal Mex3c splicing (Fig. 5A). In $t r / t r$ mice, three types of transcripts were observed from this locus by RT-PCR and sequencing (Fig. 5A and $\mathrm{B}$ ). These were the hybrid transcripts between Mex3c exon 2 and gal-neo (transcript 1); normal Mex3c mRNA transcripts (transcript 2); and transcripts containing a vector-derived exon between Mex 3c exon 2 and Mex3c exon 3 (transcript 3). The vector-derived exon in transcript 3 contains multiple stop codons disrupting the translation of MEX3C ${ }^{652 \mathrm{AA}}$ and MEX3C ${ }^{464 \mathrm{AA}}$, but a product of MEX3C $\mathrm{C}^{372 \mathrm{AA}}$ (predicted from multiple human and mouse cDNA records in GenBank; Li X et al. 2014, unpublished observations) could be expressed. Thus, removing the SA sequence from the integrated trapping vector by cre-mediated

Table 2 Blood biochemical profiles and food intakes of ob/ob mice and tr/tr;ob/ob mice. ${ }^{a}$ Mice were around 3 months old and were fasted for $4 \mathrm{~h}$ before blood collection. $+\mathrm{I}+$ and $o b / o b$ data were all from males. tr/tr;ob/ob mice included four males and two females, but values for males and females were similar and thus are combined. Tukey's post-tests were performed following one-way ANOVA

\begin{tabular}{|c|c|c|c|}
\hline \multirow[b]{2}{*}{ Measurement } & \multicolumn{3}{|c|}{ Levels for each group } \\
\hline & $+1+$ & ob/ob & tr/tr;ob/ob \\
\hline Glucose (mg/dl) & $164.8 \pm 7.1$ & $551.1 \pm 6.4$ & $213.5 \pm 5.5$ \\
\hline Insulin (ng/ml) & $1.0 \pm 0.2$ & $12.0 \pm 4.0$ & $6.6 \pm 2.9$ \\
\hline Triglycerides (mg/dl) & $132.0 \pm 13$ & $519.1 \pm 76.8$ & $138.0 \pm 27.5$ \\
\hline Total cholesterol (mg/dl) & $116.2 \pm 6.6$ & $193.0 \pm 31.1$ & $151.4 \pm 15.2$ \\
\hline
\end{tabular}

\begin{tabular}{|c|c|c|}
\hline \multicolumn{3}{|c|}{$P$ values } \\
\hline$+I+\sim o b / o b$ & $a b / o b \sim t r / t r ; o b / o b$ & $+I+\sim$ tr/tr;ob/ob \\
\hline$<0.0001$ & $<0.0001$ & $<0.0001$ \\
\hline$<0.01$ & NS & $<0.05$ \\
\hline$<0.0001$ & $<0.0001$ & NS \\
\hline$<0.05$ & NS & NS \\
\hline
\end{tabular}

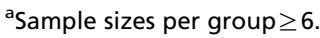

http://joe.endocrinology-journals.org DOI: 10.1530/JOE-14-0071
(C) 2014 Society for Endocrinology Printed in Great Britain
Published by Bioscientifica Ltd 
A
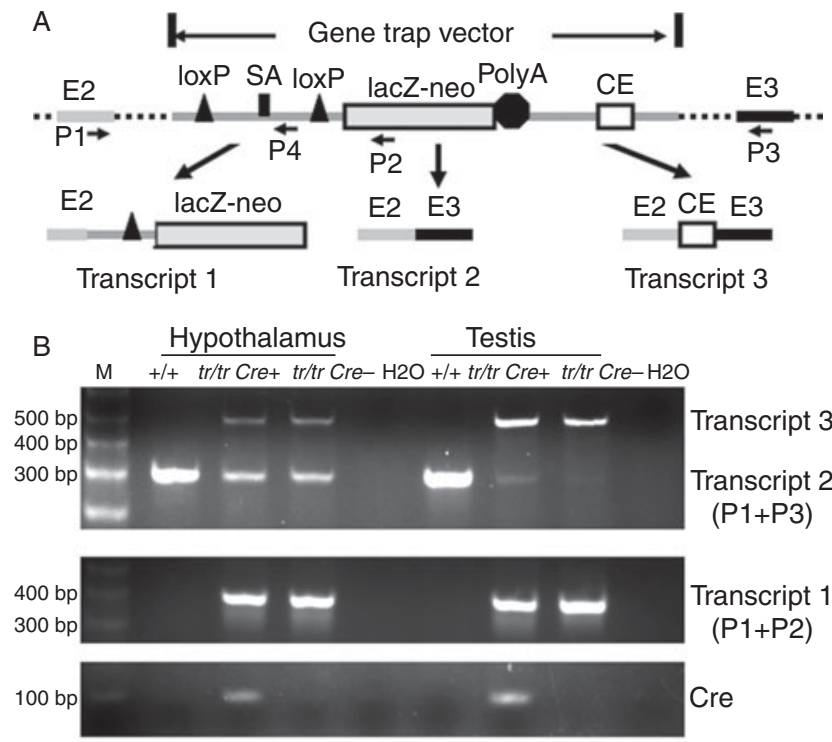

C

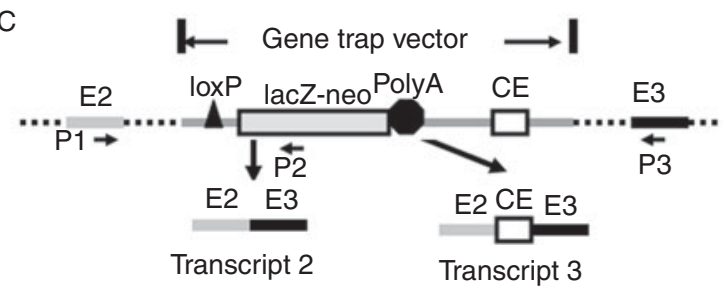

Figure 5

Strategy for cre-mediated SA sequence removal in Mex3c gene trap mice. (A) Elements of the gene trap vector and three types of transcripts from the trapped Mex3c allele. E2 and E3 indicate exon 2 and exon 3 of Mex3c gene. In an alternative splicing form (NCBI NM_001039214.4), exon 1 and exon 2 are spliced into one exon (not shown). P1, P2, P3, and P4 indicate primers used for PCR. CE: cryptic exon from the trapping vector. (B) Detection of the three types of transcripts in the hypothalamus and testis tissues of $t r / t r$ mice. All PCR products were verified by DNA sequencing. (C) Cre-mediated SA removal eliminates transcript 1 .

recombination should eliminate transcript 1 and thus increase the expression of transcripts 2 and 3 (Fig. 5C).

To determine the role of neuronal Mex $3 \mathrm{c}$ expression in energy metabolism, Mex3ctrttr $;$ Syn 1-Cre ${ }^{+}$and $\mathrm{Mex} 3 c^{\mathrm{tr} / \mathrm{tr}}$; Syn1-Cre ${ }^{-}$mice were generated, where Syn1-cre indicates the cre transgene controlled by rat Synapsin I promoter (Zhu et al. 2001), a cre allele used for knocking out genes in neurons in energy balance studies (Cohen et al. 2001, Mori et al. 2004). Expression of cre in neurons is expected to remove the SA sequence in neurons of $t r / t r$ mice, and thus increase the neuronal expression of transcripts 2 and 3 . As antibodies detecting endogenous MEX3C are unavailable, we used qTR-PCR to detect Mex3c mRNA expression changes in Mex $3 c^{\text {tr/tr }} ;$ Syn1-Cre ${ }^{+}$mice. No detectable differences were observed in the expression of transcript 2 (normal Mex3c mRNA) between the hypothalamic tissues of Mex $3 c^{\text {tr/tr }} ;$ Syn1-Cre ${ }^{+}$and Mex $3 c^{\text {tr/tr }} ;$ Syn1-Cre ${ }^{-}$ mice. This is not surprising, because i) transcript 2 was already expressed at considerable levels in Mex $3 c^{t r / t r} ;$; Syn1$\mathrm{Cre}^{-}$mice, making the detection of subtle increase difficult; and ii) Mex3c has wide expression in nonneuronal cells in the brain. For example, Mex3c is highly expressed in the ependymal cells of the third ventricle (see Fig. 5 in Jiao et al. (2012b)), and in smooth muscle cells of the blood vessels (Lu B 2014, unpublished observations), but both do not express cre; iii) cre-mediated recombination is not $100 \%$ efficient in neurons expressing both Mex3c and cre, a phenomenon previously observed in LepR $R^{\text {loxp}}$;Syn1-Cre mice (Cohen et al. 2001); and iv) some transcripts terminate after the SV40 PolyA site, even though the SA sequence is removed by cre-mediated recombination.

Mex3 $3 c^{t r / t r} ;$ Syn1-Cre $e^{+}$and Mex3 $c^{\text {tr/tr }}$;Syn1-Cre ${ }^{-}$mice both had short stature (Fig. 6A) and were indistinguishable in growth curves (Fig. 6B). However, at the age of 5 months, $M e x 3 c^{\text {tr/tr }} ;$ Syn 1-Cre ${ }^{+}$mice had clearly bigger adipose depots than Mex 3c $c^{\text {tr/tr }}$;Syn1-Cre ${ }^{-}$mice (Fig. 6C, D, and E), although their adipose depots were still significantly smaller than those of $+1+$ mice. The low WAT composition in Mex $3 c^{t r / t r} ;$ Syn1-Cre ${ }^{+}$and Mex3 $3 c^{t r / t r} ;$ Syn1-Cre ${ }^{-}$mice explains why we could not detect body weight differences between the two groups. Histological examination of epididymal and parametrial WAT tissues revealed that Mex $3 c^{t r / t r}$;Syn1$\mathrm{Cr}^{+}$mice had larger and more developed adipocytes than Mex $3 c^{\text {tr/tr}}$;Syn1-Cre ${ }^{-}$mice (Fig. 6F). WAT with less developed adipocytes were observed in three of four Mex3 $c^{t r / t r}$;Syn1-Cre $e^{-}$mice examined, but not in $5 \mathrm{Mex} 3 \mathrm{c}^{\mathrm{tr} / \mathrm{tr}}$; Syn1-Cre ${ }^{+}$mice examined (Fig. 6F, right panel). With respect to physical activity, Mex3 $c^{\text {tr/trr }} ;$ Syn1-Cre ${ }^{+}$mice were less active than $\mathrm{Mex} 3 \mathrm{c}^{\mathrm{tr} / \mathrm{tr}}$;Syn1-Cre ${ }^{-}$mice during the light cycle, although they were as hyperactive as Mex $3 c^{\text {tr/tr }}$; Syn1-Cre ${ }^{-}$mice during the dark cycle (Fig. 6G and H).

\section{Discussion}

This work builds on our previous findings regarding the role of Mex $3 c$ in energy balance. In addition to previous observations of increased energy expenditure (Jiao et al. $2012 b$ ), the Mex3c mutation significantly increased locomotor activity. Apparently increased physical activity is the primary result of $M e x 3 c$ mutation, but is not a secondary result of reduced adiposity. Thus, increased physical activity explains in part the decreased adiposity of $t r / t r$ mice. Previously, we observed that $+/ t r$ mice had normal physical activity but increased energy expenditure, suggesting that both basal energy expenditure and

Published by Bioscientifica Ltd. 

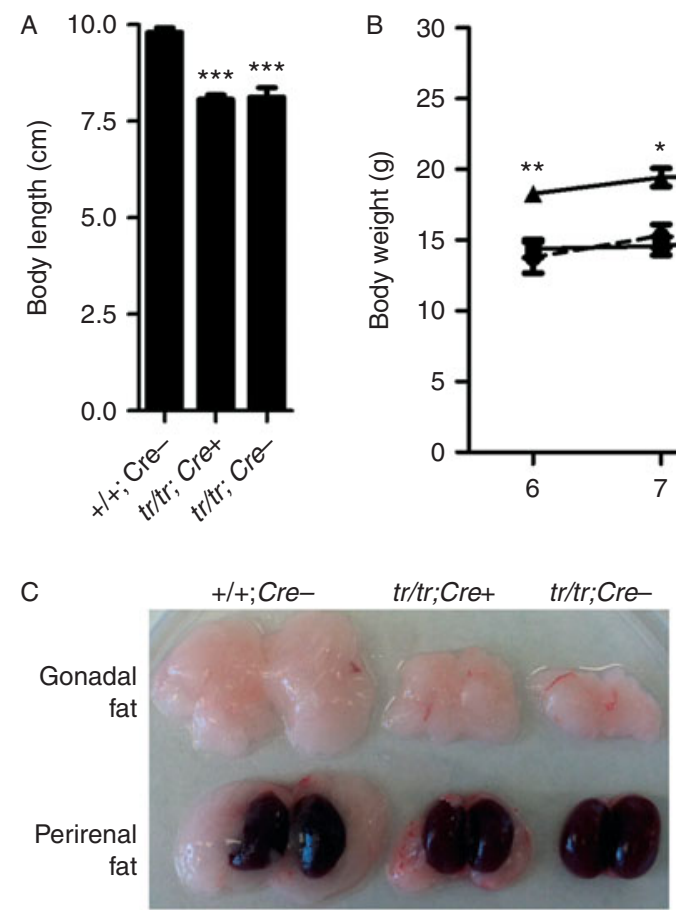

E

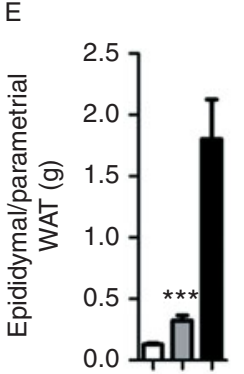

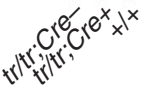

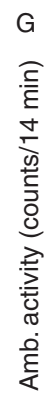
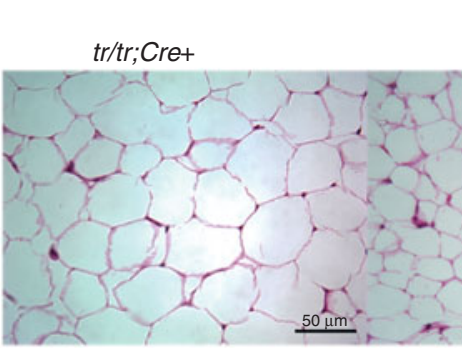

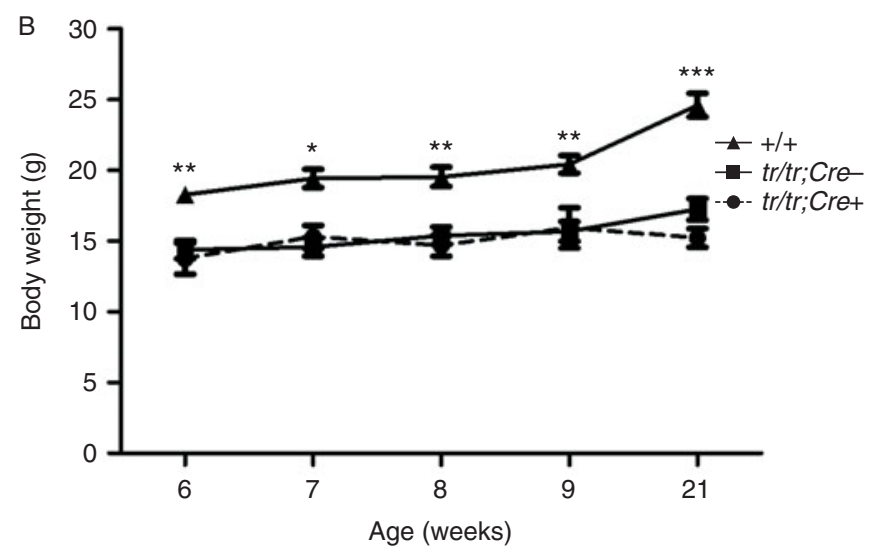

D

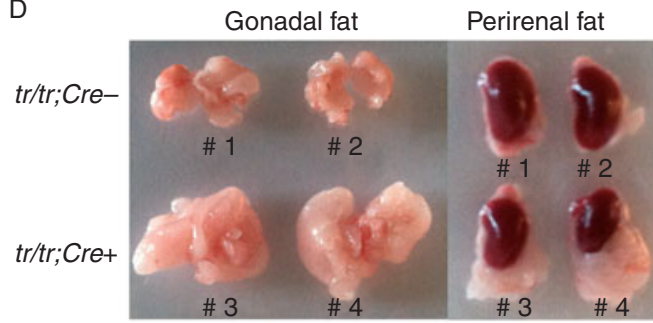

tr/tr;Cre-

tr/tr;Cre-

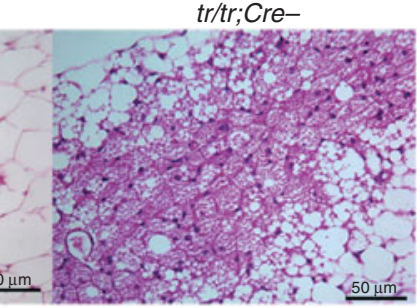

$\mathrm{H}$

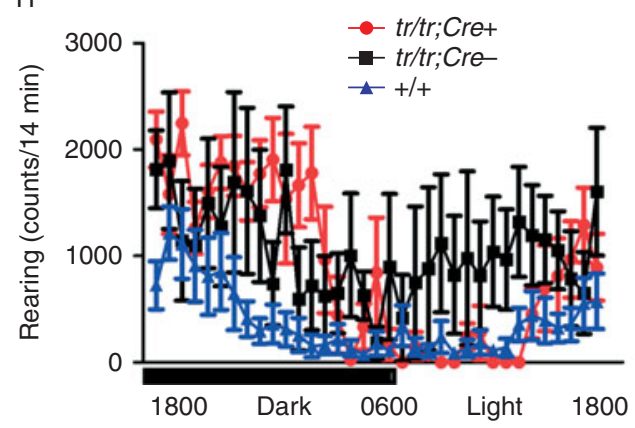

Figure 6

Neuronal expression of cre in tr/tr mice increased adiposity. (A) Cre expression did not affect body length of $\operatorname{tr} / \mathrm{tr}$ mice. $+/+$ mice $(n=10)$ were all females, Mex3c ${ }^{\text {tr/tr}}$;Syn1-Cre ${ }^{+}$mice $(n=5)$ and Mex3 $c^{\text {tr/tr }} ;$ Syn1-Cre'mice $(n=5)$ included both females and males, which showed little difference by sex. (B) Body weights of Mex3ctr/tr;Syn1-Cre ${ }^{+}$and Mex3c ${ }^{\text {tr/tr }} ;$ Syn 1-Cre mice. $+I+$ mice include $\mathrm{Cre}^{+}$and $\mathrm{Cre}^{-}$mice. (C) Representative of epididymal and perirenal WAT of male mice. (D) Parametrial and perirenal WAT tissues from two females of each group shown. (E) Weight of epididymal/parametrial WAT of normal control and mutant mice.
For Mex3 $c^{\text {tr/tr }}$;Syn 1-Cre ${ }^{-}$mice, $n=1$ male and 5 females; for Mex3 $c^{\text {tr/tr }}$;Syn 1$\mathrm{Cre}^{+}$mice, $n=1$ male and 4 females; for control mice, $n=14$ (all females). $* * * P<0.001$ by $t$-test between $\mathrm{cre}^{+}$and $\mathrm{cre}^{-}$mutants. $(\mathrm{F})$ Hematoxylin and eosin-stained epididymal WAT sections. Scale bars: $50 \mu \mathrm{m}$. (G) Ambulatory activity of cre-positive and negative mutant females. $(H)$ Rearing activity of cre-positive and negative mutant females. ( $G$ and $H$ ) Data were collected from 4 Mex3 $\mathrm{C}^{\text {tr/tr }}$;Syn 1-Cre ${ }^{+}, 4$ Mex3 $\mathrm{C}^{\text {tr/tr }}$;Syn 1-Cre ${ }^{-}$, and $9+/+$ female mice. Due to limited numbers of mutant mice available, statistical testing was not done.

Published by Bioscientifica Ltd. 
physical activity accounted for decreased adiposity of $t r / t r$ mice. $+/$ tr mice had normal physical activity but both $t r / t r$ mice and $t r / t r ; o b / o b$ mice had increased physical activity, suggesting a dose effect of Mex3c in the regulation of physical activity. Food intake of $t r / t r$ mice is reduced in absolute amount but not after normalized to body mass. Due to the large difference of body size between control and mutant mice, it is still unclear whether food intake is affected in $t r / t r$ mice.

The CNS most likely plays an important role in the perturbed energy balance of Mex $3 \mathrm{c}$ mutant mice. This idea is supported by the observations of essentially normal adipose tissue gene expression profiles, and normal absorption of food lipids in $t r / t r$ mice. More importantly, neuronal expression of cre significantly increased WAT accumulation in $t r / t r$ mice (although cre-positive mutant mice still have less fat accumulation compared with normal control mice).

Many factors (e.g., early termination at the PolyA site, and introduction of additional transcript forms) may explain our failure to observe increased in Mex3c expression in Mex3c ${ }^{\text {tr/trt}}$;Syn1-Cre $e^{+}$mice compared with $\mathrm{Mex} 3 \mathrm{c}^{\mathrm{tr} / \mathrm{tr}}$;Syn1$\mathrm{Cre}^{-}$mice. Mex $3 \mathrm{c}$ could only be partially re-activated even in $\mathrm{cre}^{+}$neurons of mutant mice, which explained why Mex $3 c^{\text {tr/tr }} ;$ Syn1-Cre ${ }^{+}$mice still had significantly reduced adiposity compared with normal control mice. The greater adipose accumulation in cre-positive mutants vs crenegative mutants is most likely the result of cre-mediated SA sequence removal, which increased Mex $3 c$ expression in a subpopulation of Mex3c-expressing neurons. Cre-positive mutants also had reduced physical activity compared with cre-negative mutants during the light cycle, which might be one reason for their greater adiposity. Due to challenges associated with generating larger numbers of $\mathrm{Cre}^{+}$and $\mathrm{Cre}^{-}$ mutant mice of the same sex and similar age, we only compared $4 \mathrm{Cre}^{+}$and $4 \mathrm{Cre}^{-}$mutant mice. More mutant mice need to be compared to confirm the data.

While Syn1-Cre mice also express cre in the testis (Cohen et al. 2001), this does not explain their increased adiposity. Syn1-Cre mice have been used to knock out Socs3 and LeptinR in neurons to study energy balance (Cohen et al. 2001, Mori et al. 2004), and a recombinationindependent effect of cre on adiposity has not been observed. In addition, many cre transgenic strains are maintained on an FVB/N background (the background of mice used in this study), and cre is not reported to cause increased adiposity in this background. Cre expression increased adiposity, but did not affect body length of $t r / t r$ mice, confirming that different systems are affected by the mutation to cause these phenotypes. The CNS is involved in the regulation of physical activity and basal energy expenditure (Kong et al. 2012, Xi et al. 2012). The role of neuronal Mex3c in basal energy expenditure remains unclear. A direct comparison of energy expenditure between control and mutant mice is problematic as they have significantly different body sizes and adiposity. We collected energy expenditure data for four cre + and four cre - mutant mice, but saw no differences between the two groups. Values varied widely, even among individuals of the same genotype. Thus, these data were inconclusive and not reported. We do not know whether neuronal MEX3C deficiency fully underlies the reduced adiposity. Answering these questions awaits the availability of a Mex3c-conditional knockout mouse model.

Our data explain why the Mex3c mutation fully protected mice in this study from diet-induced obesity and associated syndromes, and significantly improved glucose and lipid metabolism in $o b / o b$ mice. These observations also suggest that genes regulated by Mex3c could be therapeutic targets for obesity and diabetes. Agrp and POMC neurons have no or low Mex3c expression (Jiao et al. 2012b). Determining the identity of the neurons expressing Mex3c and the neural circuits affected in mutant mice will shed new light on how energy expenditure and voluntary activities are regulated. Identifying mRNA targets of the RNA-binding protein MEX3C that are involved in energy metabolism will not only improve our understanding of MEX3C function at the molecular level, but could help to develop new drugs to control and treat obesity in the future.

In summary, we found that one mechanism though which the Mex $3 c$ mutation decreases adiposity is increased locomotor activity. Neuronal Mex3c may play an important role in regulating energy balance.

\section{Declaration of interest}

The authors declare that there is no conflict of interest that could be perceived as prejudicing the impartiality of the research reported.

\section{Funding}

This research did not receive any specific grant from any funding agency in the public, commercial or not-for-profit sector.

\section{Acknowledgements}

The authors thank Dr Ryan Temel (Department of Pathology, Wake Forest University Health Sciences) for providing sucrose polybehenate, and Ms Karen Klein (Translational Science Institute, Wake Forest University Health Sciences) for editing the manuscript.

Published by Bioscientifica Ltd. 


\section{References}

Agoulnik AI, Lu B, Zhu Q, Truong C, Ty MT, Arango N, Chada KK \& Bishop CE 2002 A novel gene, Pog, is necessary for primordial germ cell proliferation in the mouse and underlies the germ cell deficient mutation, gcd. Human Molecular Genetics 11 3047-3053. (doi:10.1093/hmg/11.24.3047)

Buchet-Poyau K, Courchet J, Le Hir H, Seraphin B, Scoazec JY, Duret L, Domon-Dell C, Freund JN \& Billaud M 2007 Identification and characterization of human Mex-3 proteins, a novel family of evolutionarily conserved RNA-binding proteins differentially localized to processing bodies. Nucleic Acids Research 35 1289-1300. (doi:10.1093/nar/gkm016)

Burrell RA, McClelland SE, Endesfelder D, Groth P, Weller MC, Shaikh N, Domingo E, Kanu N, Dewhurst SM, Gronroos E et al. 2013 Replication stress links structural and numerical cancer chromosomal instability. Nature 494 492-496. (doi:10.1038/nature11935)

Cano F \& Lehner PJ 2013 A novel post-transcriptional role for ubiquitin in the differential regulation of MHC class I allotypes. Molecular Immunology 55 135-138. (doi:10.1016/j.molimm.2012.10.015)

Cano F, Bye H, Duncan LM, Buchet-Poyau K, Billaud M, Wills MR \& Lehner PJ 2012 The RNA-binding E3 ubiquitin ligase MEX-3C links ubiquitination with MHC-I mRNA degradation. EMBO Journal 31 3596-3606. (doi:10.1038/emboj.2012.218)

Chen N, Liu L, Zhang Y, Ginsberg HN \& Yu YH 2005 Whole-body insulin resistance in the absence of obesity in FVB mice with overexpression of Dgat1 in adipose tissue. Diabetes 54 3379-3386. (doi:10.2337/diabetes. 54.12.3379)

Ciosk R, DePalma M \& Priess JR 2004 ATX-2, the C. elegans ortholog of ataxin 2, functions in translational regulation in the germline. Development 131 4831-4841. (doi:10.1242/dev.01352)

Ciosk R, DePalma M \& Priess JR 2006 Translational regulators maintain totipotency in the Caenorhabditis elegans germline. Science $\mathbf{3 1 1}$ 851-853. (doi:10.1126/science.1122491)

Cohen P, Zhao C, Cai X, Montez JM, Rohani SC, Feinstein P, Mombaerts P \& Friedman JM 2001 Selective deletion of leptin receptor in neurons leads to obesity. Journal of Clinical Investigation 108 1113-1121. (doi:10.1172/JCI200113914)

Draper BW, Mello CC, Bowerman B, Hardin J \& Priess JR 1996 MEX-3 is a $\mathrm{KH}$ domain protein that regulates blastomere identity in early C. elegans embryos. Cell 87 205-216. (doi:10.1016/S0092-8674(00)81339-2)

George SK, Jiao Y, Bishop CE \& Lu B 2012 Oxidative stress is involved in age-dependent spermatogenic damage of Immp2l mutant mice. Free Radical Biology \& Medicine 52 2223-2233. (doi:10.1016/ j.freeradbiomed.2012.04.003)

Guzman B, Cormand B, Ribases M, Gonzalez-Nunez D, Botey A \& Poch E 2006 Implication of chromosome 18 in hypertension by sibling pair and association analyses: putative involvement of the RKHD2 gene. Hypertension 48 883-891. (doi:10.1161/01.HYP.0000244085.52918.a0)

Hu CC, Qing K \& Chen Y 2004 Diet-induced changes in stearoyl-CoA desaturase 1 expression in obesity-prone and -resistant mice. Obesity Research 12 1264-1270. (doi:10.1038/oby.2004.160)

Huang NN, Mootz DE, Walhout AJM, Vidal M \& Hunter CP 2002 MEX-3 interacting proteins link cell polarity to asymmetric gene expression in Caenorhabditis elegans. Development 129 747-759.

Hunter CP \& Kenyon C 1996 Spatial and temporal controls target pal-1 blastomere-specification activity to a single blastomere lineage in
C. elegans embryos. Cell 87 217-226. (doi:10.1016/S0092-8674(00) 81340-9)

Jadhav S, Rana M \& Subramaniam K 2008 Multiple maternal proteins coordinate to restrict the translation of C. elegans nanos-2 to primordial germ cells. Development 135 1803-1812. (doi:10.1242/dev.013656)

Jandacek RJ, Heubi JE \& Tso P 2004 A novel, noninvasive method for the measurement of intestinal fat absorption. Gastroenterology $\mathbf{1 2 7}$ 139-144. (doi:10.1053/j.gastro.2004.04.007)

Jiao Y, Bishop CE \& Lu B 2012a Mex3c regulates insulin-like growth factor 1 (IGF1) expression and promotes postnatal growth. Molecular Biology of the Cell 23 1404-1413. (doi:10.1091/mbc.E11-11-0960)

Jiao Y, George SK, Zhao Q, Hulver MW, Hutson SM, Bishop CE \& Lu B $2012 b$ Mex3c mutation reduces adiposity and increases energy expenditure. Molecular and Cellular Biology 32 4350-4362. (doi:10.1128/ MCB.00452-12)

Kong D, Tong Q, Ye C, Koda S, Fuller PM, Krashes MJ, Vong L, Ray RS, Olson DP \& Lowell BB 2012 GABAergic RIP-Cre neurons in the arcuate nucleus selectively regulate energy expenditure. Cell $\mathbf{1 5 1}$ 645-657. (doi:10.1016/j.cell.2012.09.020)

Mori H, Hanada R, Hanada T, Aki D, Mashima R, Nishinakamura H, Torisu T, Chien KR, Yasukawa H \& Yoshimura A 2004 Socs3 deficiency in the brain elevates leptin sensitivity and confers resistance to dietinduced obesity. Nature Medicine 10 739-743. (doi:10.1038/nm1071)

Musco G, Stier G, Joseph C, Castiglione Morelli MA, Nilges M, Gibson TJ \& Pastore A 1996 Three-dimensional structure and stability of the KH domain: molecular insights into the fragile X syndrome. Cell $\mathbf{8 5}$ 237-245. (doi:10.1016/S0092-8674(00)81100-9)

Petrovic N, Walden TB, Shabalina IG, Timmons JA, Cannon B \& Nedergaard J 2010 Chronic peroxisome proliferator-activated receptor gamma (PPAR $\gamma$ ) activation of epididymally derived white adipocyte cultures reveals a population of thermogenically competent, UCP1-containing adipocytes molecularly distinct from classic brown adipocytes. Journal of Biological Chemistry 285 7153-7164. (doi:10.1074/ jbc.M109.053942)

Siomi H, Matunis MJ, Michael WM \& Dreyfuss G 1993 The pre-mRNA binding $\mathrm{K}$ protein contains a novel evolutionarily conserved motif. Nucleic Acids Research 21 1193-1198. (doi:10.1093/nar/21.5.1193)

Sutherland LN, Capozzi LC, Turchinsky NJ, Bell RC \& Wright DC 2008 Time course of high-fat diet-induced reductions in adipose tissue mitochondrial proteins: potential mechanisms and the relationship to glucose intolerance. American Journal of Physiology. Endocrinology and Metabolism 295 E1076-E1083. (doi:10.1152/ajpendo.90408.2008)

Wu J, Bostrom P, Sparks LM, Ye L, Choi JH, Giang AH, Khandekar M, Virtanen KA, Nuutila P, Schaart G et al. 2012 Beige adipocytes are a distinct type of thermogenic fat cell in mouse and human. Cell $\mathbf{1 5 0}$ 366-376. (doi:10.1016/j.cell.2012.05.016)

Xi D, Gandhi N, Lai M \& Kublaoui BM 2012 Ablation of Sim1 neurons causes obesity through hyperphagia and reduced energy expenditure. PLOS ONE 7 e36453. (doi:10.1371/journal.pone.0036453)

Zhang Y, Proenca R, Maffei M, Barone M, Leopold L \& Friedman JM 1994 Positional cloning of the mouse obese gene and its human homologue. Nature 372 425-432. (doi:10.1038/372425a0)

Zhu Y, Romero MI, Ghosh P, Ye Z, Charnay P, Rushing EJ, Marth JD \& Parada LF 2001 Ablation of NF1 function in neurons induces abnormal development of cerebral cortex and reactive gliosis in the brain. Genes and Development 15 859-876. (doi:10.1101/gad.862101)

Received in final form 18 March 2014

Accepted 14 April 2014

Accepted Preprint published online 16 April 2014 http://joe.endocrinology-journals.org DOI: 10.1530/JOE-14-0071
() 2014 Society for Endocrinology Printed in Great Britain
Published by Bioscientifica Ltd. 